\title{
O impacto dos aspectos organizacionais sobre a percepção de melhoria em desenvolvimento de produtos
}

\author{
The impact of organizational aspects on the improvement \\ perception of the new product development
}

\author{
Sanderson César Macedo Barbalho' \\ Henrique Rozenfeld ${ }^{1}$
}

\begin{abstract}
Resumo: Este trabalho analisa a relação entre atores das unidades organizacionais do processo de desenvolvimento de produtos (PDP), assim como entre o papel exercido por eles e a sua percepção de melhoria do processo. O contexto do trabalho é o de uma empresa com estrutura funcional na qual foram aplicadas melhorias no PDP. Pessoas de engenharia, manufatura e marketing foram entrevistadas. Detectou-se que a percepção de melhoria é influenciada pelo departamento de origem do entrevistado, mas que o papel do entrevistado no PDP é mais determinante sobre sua percepção que a área funcional na qual ele está inserido.
\end{abstract}

Palavras-chave: Processo de desenvolvimento de produtos. Estrutura organizacional. Percepção de melhoria.

Abstract: This article analyzes the relationship between the responsibilities of organizational units in new product development (NPD) and their improvement perception. The research was carried out in a functionally oriented company in which some improvement actions were performed. Some employees from the engineering, manufacturing and marketing departments were interviewed. It was found that improvement perception is driven by the functional department the individual belongs to. But, the role performed by the individual in NPD can better explain his/her perception about improvements.

Keywords: New product development. Organizational structure. Improvement perception.

\section{Introdução}

O processo de desenvolvimento de produtos (PDP) lida com uma dicotomia intrínseca: deve ser criativo para que os novos produtos abram novas oportunidades de mercado para a empresa e deve ser pragmático para que as tecnologias dominadas pela empresa, assim como sua estrutura de marketing e de manufatura sejam potencializadas. Essa dicotomia se estende ao trabalho de quem projeta e desenvolve produtos. O engenheiro quer testar novas tecnologias e o vendedor quer novos mercados, mas o pessoal de manufatura quer algo que não modifique muito a estrutura de fabricação da empresa. $\mathrm{O}$ vendedor quer novos mercados, mas é a manufatura que terá que desenvolver novas estruturas de distribuição, novos fornecedores, novas parcerias. $\mathrm{O}$ time de projeto quer novas tecnologias, mas os prazos de desenvolvimento comumente o empurram para usar pequenas variações daquela que é dominada pela empresa. O gerente do produto quer que o resultado do projeto atenda às especificações que lhe foram passadas, mas o marketing altera as especificações com frequência, pois o mercado muda. A alta direção sabe que um projeto é resultado do compromisso entre atendimento das especificações com um determinado grau de qualidade, cumprimento dos prazos e controle dos custos do projeto e do produto. Esse compromisso, entretanto, nem sempre é claramente comunicado para gerentes e times de projeto.

Este trabalho analisa a relação entre uma determinada unidade organizacional envolvida no processo de desenvolvimento de produtos, seu papel no PDP e sua percepção quanto à melhoria desse processo. Nesse sentido, o artigo articula duas importantes áreas do estudo do PDP: sua estrutura

\footnotetext{
' Núcleo de Manufatura Avançada, Departamento de Engenharia de Produção, Escola de Engenharia de São Carlos - EESC, Universidade de São Paulo - USP, Av. Trabalhador São-carlense, 400, CEP 13566-590, São Carlos - SP, Brasil,

E-mails: scmb@sc.usp.br; roz@sc.usp.br
} 
organizacional e a melhoria do processo. É sabido que a efetividade de uma forma de organização do PDP depende das condições de mercado e tecnologia às quais a empresa está submetida. São conhecidos os indicadores de desempenho mais fortemente vinculados a estruturas funcionais e projetizadas. Por outro lado, sabe-se que a implementação de melhorias de processo deve resultar em melhoria em indicadores de desempenho do processo melhorado. No caso do PDP, em se aplicando melhores práticas descritas em organizações profissionais e científicas, espera-se diagnosticar melhoria em prazos, custos e qualidade.

Entretanto, como os engenheiros envolvidos no projeto de um novo produto veem as melhorias aplicadas ao processo de desenvolvimento? E como as pessoas de manufatura e de marketing veem? E, dentro de um determinado projeto, como os gerentes de produto, a alta direção envolvida e os executores de atividades técnicas veem as melhorias? O que é melhoria, para um desses atores, pode não ser para outro.

O objetivo deste estudo é resultado desse conjunto de reflexões e pode ser assim sumarizado: analisar como um conjunto de melhorias em desenvolvimento de produtos é percebido pelos diferentes atores envolvidos nesse processo.

\section{Método de pesquisa e seu contexto}

Este artigo descreve a avaliação de um trabalho de pesquisa ação com a duração de 30 meses. A pesquisa ação focou a melhoria do processo de desenvolvimento de produtos (PDP) da empresa em questão. O referencial para a pesquisa ação adotou uma nova versão do método proposto por Coughlan e Coghlan (2009), que indica as fases: diagnóstico, planejamento da ação, realização da ação e avaliação da ação. Após a realização de alguns ciclos de melhoria, os quais podem ser visualizados em Barbalho (2006), foi realizada uma avaliação final, escopo deste artigo, a qual se insere na etapa final do processo de pesquisa ação descrita pelos autores acima.

Na seção 6, são sumarizadas as intensas alterações no PDP da empresa, realizadas durante a pesquisa ação. Para cumprir a avaliação, foi realizado um estudo de caso holístico (YIN, 2001). Tal metodologia permitiu um aprofundamento na avaliação dos resultados do trabalho visto que o pesquisador foi o responsável pela pesquisa ação realizada anteriormente e a utilização do ferramental do estudo de caso holístico possibilitou maior controle dos aspectos subjetivos da avaliação de um trabalho de pesquisa ação, conforme descreve Thiollent (2002). Além disso, o autor pertence atualmente ao quadro de colaboradores da empresa, o que permite realizar uma análise mais aprofundada e trazer insights qualitativos importantes para a avaliação da evolução do PDP da empresa.
Assim sendo, foram realizadas entrevistas com um conjunto de pessoas envolvidas em projetos de novos produtos, oriundas de diversos escalões da firma e pertencentes aos três principais departamentos relacionados ao desenvolvimento de novos produtos: engenharia, marketing e manufatura. O Quadro 2, apresentado no item 7 , mostra o quantitativo do pessoal entrevistado: 20 pessoas. O quadro demonstra também como os entrevistados estão divididos por área funcional e qual o seu papel no PDP da empresa. Os entrevistados representam $100 \%$ do pessoal de engenharia envolvido com o desenvolvimento de novos produtos, $100 \%$ das chefias dos departamentos de manufatura envolvidos com os projetos de desenvolvimento, uma vez que são os chefes de setor que participam mais fortemente das atividades de fabricação e montagem dos protótipos, 2/3 do pessoal de marketing envolvido, sendo o principal executivo de vendas e a coordenadora de marketing da firma. Este pessoal da área comercial representa $33 \%$ de todo corpo de vendas técnicas com base na empresa, uma vez que a maioria do pessoal da área comercial trabalha diretamente em campo, não participando das atividades e decisões de marketing relacionadas ao projeto de novos produtos.

Considerando a extratificação do pessoal pesquisado com relação ao seu papel no PDP da empresa, a amostra abrangeu $100 \%$ dos líderes de projeto, $78 \%$ dos gerentes funcionais envolvidos, metade da alta direção da empresa e $100 \%$ do pessoal técnico envolvido nos projetos. É importante observar que os líderes de projeto assumem duplo papel no PDP da empresa, uma vez que, mesmo liderando um projeto participam de outros como executores de atividades técnicas. Para evitar conflito de papéis, ao longo das entrevistas foi enfatizado aos líderes que se posicionassem acerca dos projetos nos quais lideram as atividades. Os comentários acerca dos demais projetos foram desconsiderados para efeito da confecção dos gráficos apresentados no item 7 deste trabalho. Adicionalmente, foi solicitado aos entrevistados que comentassem suas respostas de maneira a reforçar uma análise mais qualitativa dos dados.

Ao grupo pesquisado foram submetidas afirmações quanto à melhoria do PDP da empresa e os pesquisados respondiam com base na seguinte escala: -2 , discordo totalmente; -1 , discordo $;+1$, concordo $;+2$, concordo totalmente. $\mathrm{O}$ zero da escala apresentada nos gráficos expostos no item 7 foi conseguido apenas quando cruzados os dados do pessoal por grupo pesquisado. No caso de a pessoa pesquisada considerar que não sabia se uma determinada melhoria ocorreu ou não, sua resposta foi considerada nula, não entrando qualquer valor na confecção das médias apresentadas nos gráficos que vão da Figura 4 até a Figura 11. 
A seguir é apresentado o referencial teórico do trabalho.

\section{Organização do processo de desenvolvimento de produtos}

Os temas mais fortemente discutidos pelos autores de desenvolvimento de produtos no que tange à organização necessária a esse processo são a estrutura organizacional que uma empresa estabelece para seu PDP e os atores organizacionais que participam do processo.

Em Clark e Fujimoto (1991, p. 248), há uma fundamentada discussão sobre o que os autores chamam de "[...] dimensões formais e informais de liderança e organização". Os autores argumentam que o esforço para organizar o PDP é fundamentado na busca de soluções para dois problemas básicos: (1) como projetar, construir e testar partes e subsistemas de forma que cada elemento atinja um alto nível de desempenho técnico; e (2) como atingir alto grau de integridade do produto, uma vez que as partes e subsistemas comumente são projetados separadamente. A integridade do produto teria duas dimensões. Internamente, significaria a harmonia com a qual as partes funcionam quando unidas. Externamente significaria o grau em que a experiência no uso do produto como um todo atende às expectativas do consumidor.

Do ponto de vista organizacional, segundo os autores, o desempenho técnico tem relação com o grau de especialização das áreas funcionais da empresa, enquanto que a integridade do produto está relacionada com o grau de integração com o qual a empresa desenvolve produtos. Por exemplo, as empresas europeias de automóveis esportivos de alto padrão, que os fabricam em pequenos lotes quase artesanais, dão ênfase a áreas funcionais com alto grau de especialização técnica. Por outro lado, eletrônicos de consumo são projetados mediante a composição de times de projeto que iniciam um trabalho cooperativo já no momento em que o conceito do produto é estabelecido. Determinadas empresas desse setor criam áreas de desenvolvimento com profissionais de todas as áreas tecnológicas necessárias à engenharia de um dado produto.

Para os autores,

[...] as escolhas que uma empresa faz com relação à especialização e integração no PDP refletem a natureza da tecnologia, o caráter dos mercados que ela serve e a intensidade da competição (idem ibidem, p. 250).

Analisando as empresas do setor automobilístico, os autores chegaram a quatro formas básicas de organização do desenvolvimento de produtos, as quais são apresentadas na Figura 1.
A estrutura funcional ilustrada na Figura 1 é utilizada para enfatizar a especialização, enquanto a integração do esforço de desenvolvimento é estabelecida por procedimentos, regras, especificações detalhadas etc. As demais estruturas apresentam a figura do gerente de produto cuja função varia de mero coordenador do esforço de engenharia na estrutura peso-leve a controlador efetivo dos recursos alocados ao projeto, caso das estruturas peso-pesado e time de projeto. Adicionalmente, nessas últimas estruturas, o gerente de produto é responsável pela manutenção do conceito do produto ao longo do PDP, o que influencia fortemente a possibilidade de manutenção da integridade externa do produto.

Finalmente, Clark e Fujimoto (1991) apontam que há importante dependência da integridade interna do produto com relação à capacidade da empresa em gerenciar seus fornecedores. Esse tema é extensamente discutido em Amaral (1999).

Wheelwright e Clark (1993), Clausing (1993), e Ulrich e Eppinger (2000) explicitamente utilizam o modelo proposto por Clark e Fujimoto, acima descrito. O PMBOK (PROJECT MANAGEMENT INSTITUTE, 2005) modela uma série de estruturas organizacionais pelas quais a maioria das empresas gerencia seus projetos. O padrão acrescenta à análise de Clark e Fujimoto (1991), uma estrutura denominada matricial fraca que é intermediária entre a funcional e a estrutura peso-leve.

O PMBOK apresenta o que denomina de "[...] principais características relacionadas a projeto da maioria das estruturas das organizações", as quais consolidam uma série de elementos importantes no projeto da estrutura organizacional de desenvolvimento em uma determinada empresa. Essas características são apresentadas na Tabela 1.

Pode-se considerar que o gerente de produto descrito por Clark e Fujimoto (1991) é o gerente de projetos do PMBOK quando o projeto considerado é de desenvolvimento de um novo produto.

Nonaka e Takeuschi (1997) apresentam uma interessante discussão acerca da forma de organização que consideram mais adaptada aos processos de criação de conhecimento, dentre os quais se pode posicionar o PDP. Segundo os autores, essa estrutura pode ser chamada "organização em hipertexto" sendo "[... ] constituída de níveis interconectados, ou contextos: o sistema de negócios, a equipe de projeto e a base de conhecimento" (NONAKA; TAKEUSHI, 1994, p. 194).

O sistema de negócios caracterizaria o nível no qual são realizadas as operações normais da rotina da empresa, enquanto que a base de conhecimento incorpora a visão da empresa e a cultura organizacional para liberar o conhecimento tácito e a tecnologia para disponibilizar o conhecimento explícito. A equipe de projeto é responsável pelo desenvolvimento efetivo 


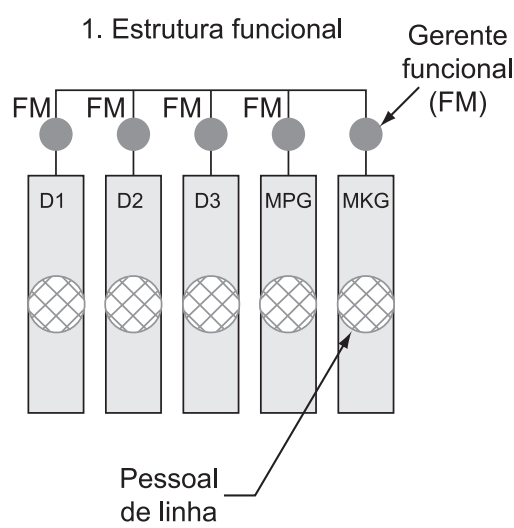

3. Gerente de produto peso-pesado

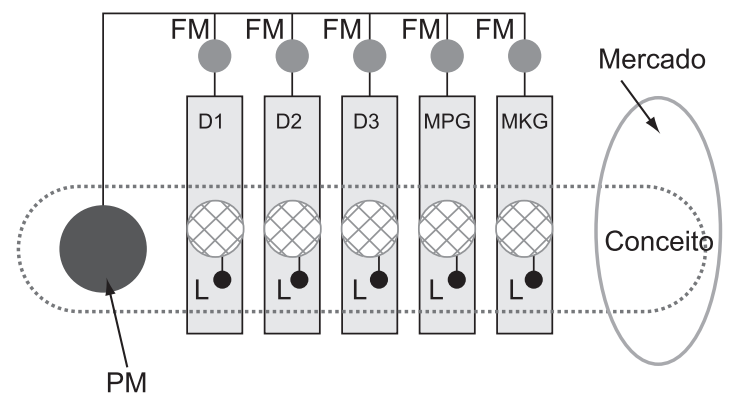

2. Gerente de produto peso-leve

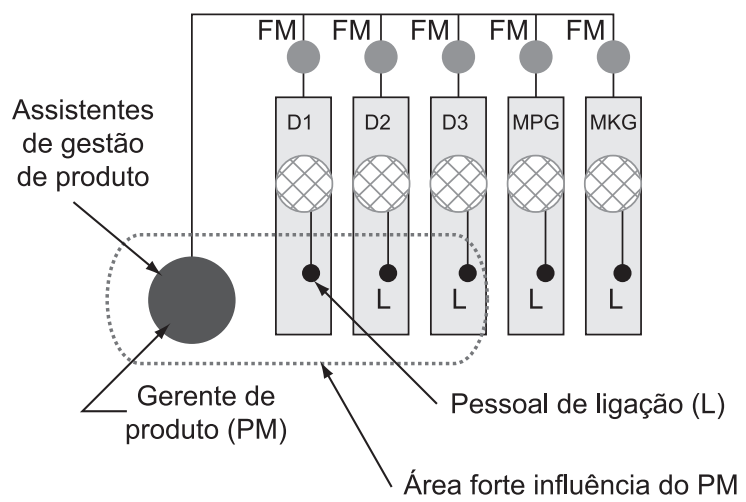

4. Time de execução do projeto

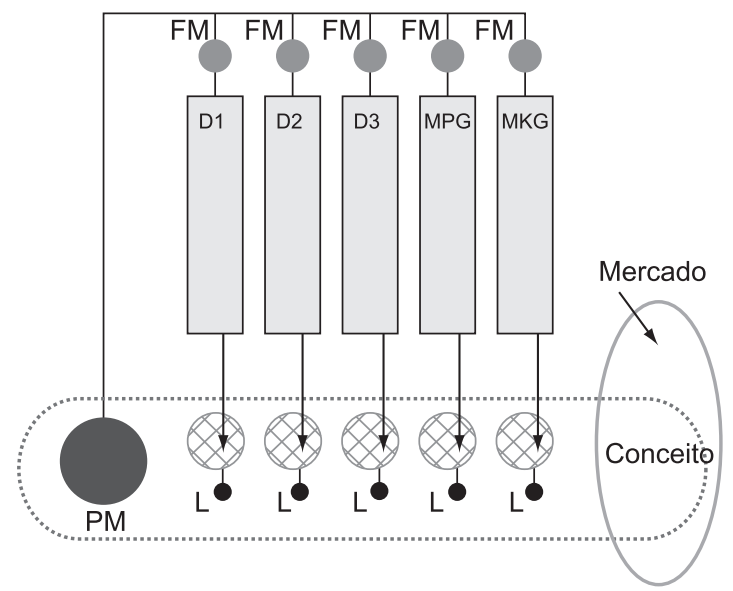

Figura 1. Quatro modos de organização do desenvolvimento. (Fonte: CLARK; FUJIMOTO, 1991, p. 254).

do produto. Segundo eles, a principal característica da organização em hipertexto é a capacidade que seus membros têm de mudar de contexto. Na linguagem de Clark e Fujimoto (1991) e do PMBOK, a organização de hipertexto é uma estrutura matricial. As atividades de rotina e de projeto são contextos diferentes aos quais as pessoas estariam submetidas nas empresas que desenvolvem produtos.

As principais unidades organizacionais envolvidas em projetos de desenvolvimento de produtos estão ilustradas no Quadro 1 conforme descrito em Clark e Fujimoto (1991), Wheelwright e Clark (1992), Clausing (1993), Cooper e Kleindshmidt (1998) e Ulrich e Eppinger (2000).

Deve-se observar que no Quadro 1 há dois tipos diferentes de unidades organizacionais. Há os departamentos da empresa, ou seja, as áreas funcionais mais fortemente envolvidas no PDP: engenharia, manufatura e marketing. Em empresas funcionais essas unidades são os principais atores envolvidos no PDP. Há, por outro lado, unidades organizacionais que representam atores importantes na estrutura de desenvolvimento da empresa, cujos papéis são relevantes principalmente em estruturas matriciais e projetizadas.

Por exemplo, o gerente funcional tem um papel bastante intuitivo em estruturas funcionais: gerenciar sua equipe técnica e fazê-los cumprir as metas da empresa. Em estruturas matriciais, essa função é dividida com o gerente de produto e passa totalmente a este último nas estruturas projetizadas. $\mathrm{O}$ time de desenvolvimento, fundamental nas matriciais, é dispensável nas estruturas funcionais. O papel da alta direção no PDP foi paulatinamente aclarado nos anos 90 até a formalização da gestão de portfólio no modelo stage-gate ${ }^{\oplus}$, no qual seu papel é central no que concerne ao balanceamento, maximização de valor e alinhamento dos projetos com a estratégia da empresa (COOPER; KLEINDSMIDT, 1998). 
Diversos estudos de levantamento de melhores práticas em PDP apontam aspectos organizacionais como diferenciais em empresas com alto desempenho em desenvolvimento de produtos. O comprometimento da alta direção, especialmente em pontos de decisão go/kill, e a adoção de times multidisciplinares são apontados por Cooper e Kleinshmidt (1995) como os principais direcionadores do desempenho de empresas líderes em desenvolvimento. A importância dos times multifuncionais é confirmada por Griffin (1997), que diagnostica, ainda, que empresas líderes utilizam mecanismos de recompensa focados no time e mais vinculados com o reconhecimento público do que com o retorno financeiro dos integrantes dos times de projetos exitosos. Em Cooper (1998), os aspectos organizacionais são abordados sob o ponto de vista da disponibilidade dos recursos necessários aos novos projetos por parte da alta direção da empresa. Segundo o autor, o comprometimento de recursos adequados ao projeto aumenta em cerca de $45 \%$ o sucesso mercadológico e a rentabilidade dos projetos de novos produtos. Estudos de melhores práticas em PDP estiveram muito presentes no cenário internacional na década de 90 e proveram uma visão geral acerca da influência da organização do PDP no resultado geral do desenvolvimento de novos produtos. A seguir discutem-se alguns estudos cujo enfoque foi explícito em alguns elementos da organização para o PDP.

Markham e Griffin (1998) analisam o impacto de forte liderança ao longo do projeto sobre o sucesso dos novos produtos e verificam que, embora essa prática reforce o desempenho do PDP na empresa, não gera impacto significativo no sucesso mercadológico dos produtos. Khurana e Rosenthal (1998) analisam o papel do time de projeto, do gerente de projetos, do

Tabela 1. Influência da estrutura da organização nos projetos segundo o PMBOK (Fonte: PMBOK, 2005, p. 19).

\begin{tabular}{|c|c|c|c|c|c|}
\hline & \multirow[t]{2}{*}{ Funcional } & \multicolumn{3}{|c|}{ Matricial } & \multirow[t]{2}{*}{ Projetizada } \\
\hline & & Matricial fraca & Peso leve & Peso pesado & \\
\hline $\begin{array}{l}\text { Autoridade do gerente } \\
\text { de projeto }\end{array}$ & $\begin{array}{l}\text { Pouca ou } \\
\text { nenhuma }\end{array}$ & Limitada & $\begin{array}{l}\text { De baixa a } \\
\text { moderada }\end{array}$ & $\begin{array}{l}\text { De moderada } \\
\text { a alta }\end{array}$ & $\begin{array}{l}\text { De alta a quase } \\
\text { total }\end{array}$ \\
\hline $\begin{array}{l}\text { Percentual do pessoal } \\
\text { alocado em tempo } \\
\text { integral ao projeto }\end{array}$ & $\begin{array}{l}\text { Virtualmente } \\
\text { nenhum }\end{array}$ & $0-25 \%$ & $15-60 \%$ & $50-95 \%$ & $85-100 \%$ \\
\hline $\begin{array}{l}\text { Alocação do } \\
\text { gerente de projeto }\end{array}$ & Tempo parcial & Tempo parcial & Tempo integral & Tempo integral & Tempo integral \\
\hline $\begin{array}{l}\text { Designações mais } \\
\text { comuns para o papel do } \\
\text { gerente de projeto }\end{array}$ & $\begin{array}{l}\text { Coordenador de } \\
\text { projeto/líder de } \\
\text { projeto }\end{array}$ & $\begin{array}{l}\text { Coordenador de } \\
\text { projeto/líder de } \\
\text { projeto }\end{array}$ & $\begin{array}{l}\text { Gerente de } \\
\text { projeto/diretor } \\
\text { de projeto }\end{array}$ & $\begin{array}{c}\text { Gerente de } \\
\text { projeto/Gerente } \\
\text { de programa }\end{array}$ & $\begin{array}{c}\text { Gerente de } \\
\text { projeto/Gerente } \\
\text { de programa }\end{array}$ \\
\hline $\begin{array}{l}\text { Suporte administrativo } \\
\text { ao gerente de projetos }\end{array}$ & Tempo parcial & Tempo parcial & Tempo parcial & Tempo integral & Tempo integral \\
\hline
\end{tabular}

Quadro 1. Unidades organizacionais em estruturas funcionais.

\begin{tabular}{|ll|}
\hline \multicolumn{1}{|c|}{ Unid. Org. } & \multicolumn{1}{c|}{ Responsabilidades } \\
\hline Marketing & $\begin{array}{l}\text { Tem importante papel em todas as estruturas acima mencionadas. Responde pelos requisitos } \\
\text { dos consumidores, testes de mercado e plano de marketing e vendas. }\end{array}$ \\
Engenharia & $\begin{array}{l}\text { Responsável pelo projeto do produto e a engenharia de produto em estruturas funcionais. Nas } \\
\text { demais estruturas a engenharia fornece recursos humanos nas diferentes áreas tecnológicas. }\end{array}$ \\
Manufatura & $\begin{array}{l}\text { Projeto do processo no sentido de Engenharia de processo. Try-out. Identificação e gestão de } \\
\text { fornecedores. }\end{array}$ \\
Alta direção & $\begin{array}{l}\text { Responsável pela gestão de portfólio do produto, seja em nível estratégico ou nos denominados } \\
\text { gates. Responsável pela estrutura de desenvolvimento da empresa. }\end{array}$ \\
$\begin{array}{l}\text { Gerente } \\
\text { funcional }\end{array}$ & $\begin{array}{l}\text { Responsável pela alocação de recursos aos projetos e pelo acompanhamento dos resultados } \\
\text { alcançados por seus subordinados em estruturas funcionais e matriciais. }\end{array}$ \\
Time de & $\begin{array}{l}\text { Uma equipe de cerca de 20 pessoas (CLAUSING, 1993) que desenvolve o produto. É o núcleo } \\
\text { desenvolvimento projeto em estruturas matriciais e projetizadas. } \\
\text { Gerente de }\end{array}$ \\
produto & $\begin{array}{l}\text { É o responsável pelo planejamento e execução do projeto e pelo desenvolvimento e manutenção } \\
\text { da concepção do produto. A abrangência dessas funções é definida na Figura 1. }\end{array}$ \\
\hline
\end{tabular}


comitê de acompanhamento do projeto e da alta direção nas atividades relacionadas com o levantamento dos requisitos do mercado e com o planejamento das atividades de projeto. Campbell e Cooper (1999) analisam os impactos de um maior envolvimento dos clientes ao longo de um projeto de novo produto e verificam que nesses projetos há maior probabilidade de sucesso técnico do produto, mas não há impacto positivo no que concerne à organização do esforço dentro da empresa.

Matsui (2002) analisa a contribuição de departamentos de manufatura sobre o desenvolvimento de produtos e identifica que quanto maior essa participação, menores os ciclos de desenvolvimento e melhor o desempenho do produto em termos de tempos de entrega e de suporte técnico pós-venda. Sosa, Eppinger e Rowles (2004) analisam o alinhamento da estruturação do produto como subsistemas e a divisão do projeto entre grupos de trabalho. Como conclusão, os autores apontam que a modularidade do produto tem forte influência no grau de integração entre áreas funcionais em um projeto de novo produto. Millson e Wilemon (2006) estudam a influência da integração organizacional de uma dada empresa sobre os resultados dos novos produtos, tais como expectativas de lucro, potencial de vendas e sucesso em mercados já abordados e novos para a empresa. Os resultados mostram que a integração organizacional como um todo é mais impactante nos lucros, o mesmo ocorrendo quando se considera apenas a integração interna da empresa (seus departamentos e times de projeto). Quando se analisa a integração da empresa com clientes e fornecedores, o maior impacto se dá sobre o volume de vendas dos novos produtos.

McIvor, Humphreys e Cadden (2006) realizam profundo estudo de caso acerca das técnicas de envolvimento de fornecedores no início do processo de desenvolvimento de um novo produto (early supply involvement). Os autores verificam que, embora haja forte retórica no mundo corporativo acerca das parcerias com fornecedores, há, na prática, um conjunto de barreiras que as dificultam, dentre elas: (1) ênfase da gerência na concorrência entre fornecedores visando realizar contratos mais vantajosos; (2) imposições da administração central sobre as alternativas de subcontratação abertas às gerências locais; (3) resistência do time de projeto quanto à integração de engenheiros de empresas contratadas; e (4) falta de confiança entre as empresas acerca de sua estrutura de custos.

Akgün et al. (2006) realiza um estudo sóciocognitivo para verificar quais características do processo de aprendizado são mais efetivas para gerar produtos que resultem em êxito mercadológico. Os autores identificaram que a incorporação de conhecimento gerado no mercado, na manufatura e em outros departamentos da companhia em um determinado projeto é a principal influência dos aspectos cognitivos sobre o resultado do PDP. Os autores constroem o conceito de "inteligência de time" mediante o qual explicam os casos de sucesso da amostra pesquisada.

Kodama (2007) apresenta um estudo de caso que demonstra como desenvolver comunidades estratégicas entre empresas e consumidores para facilitar o atendimento de requisitos de produtos em mercados altamente dinâmicos. Chiva e Alegre (2007) analisam um grande conjunto de habilidades gerenciais em PDP quanto a diferentes estratégias de verticalização no desenvolvimento de novos produtos na indústria cerâmica. Os autores verificam que as empresas que desenvolvem produtos internamente apresentam maior capacidade gerencial que aquelas que terceirizam o projeto dos novos produtos.

Merlo e Girard (2004) utilizam a metodologia GRAI (Groupe de Recherche en Automatisation Intégrée) e a linguagem UML (Unified Modeling Language) para especificar um software adaptado às atividades de coordenação de projetos de desenvolvimento. Barreto et al. (2007) propõem uma ferramenta de suporte às atividades de planejamento dos recursos humanos envolvidos em projetos de desenvolvimento de software. A ferramenta utiliza uma lista de habilidades e perfis que deve ser continuamente atualizada e permite balancear previsões de custo, tempo, alocação de recursos e tamanho do projeto.

Verifica-se, portanto, na bibliografia primária estabelecida em periódicos indexados, que os autores que analisam a organização do PDP tendem a estudá-la tentando compreender os direcionadores de sucesso em novos produtos vinculados a aspectos organizacionais como integração interna dos departamentos da empresa, ou externa, ora com clientes, ora com fornecedores. Por outro lado, há estudos relacionados com o desenvolvimento de ferramentas gerenciais que permitam otimizar recursos em desenvolvimento de produtos. Não se observou, na bibliografia levantada, estudo acerca das diferentes percepções dos atores envolvidos no PDP quanto à melhoria no processo, o que contribuiu para a delimitação do objeto de pesquisa deste trabalho.

\section{Melhoria em desenvolvimento de produtos}

O conceito de melhoria foi popularizado a partir da experiência japonesa de gestão com base em eventos kaizen (IMAI, 1997) e, posteriormente, com os programas de gestão pela qualidade total que foram disseminados em todo o ocidente. Conceitos consolidados como o ciclo PDCA (Plan-Do-Check-Act) e a trilogia JURAN são baseados na ideia da melhoria contínua (GRYNA, 2003). O conceito de reengenharia de processos (HAMMER, 1994) foi utilizado no início 
dos anos 90 como contraponto à melhoria contínua no sentido de prover um referencial para a realização de mudanças drásticas nos processos empresariais, das quais resultaria melhoria global no desempenho do processo "reengenheirado".

Posteriormente, as teorias de gestão da mudança permitiram integrar os referenciais de melhoria contínua e mudança drástica de maneira consistente. A aprendizagem organizacional e as teorias de criação do conhecimento na empresa permitiram agregar ao referencial da melhoria contínua a necessidade de estimular e gerenciar a incorporação de habilidades ao longo dos processos de melhoria. Atualmente os chamados modelos de maturidade, tais como o CMMI (Capability Maturity Model Integration), são fortemente baseados nas teorias de melhoria contínua.

Embora o referencial da melhoria contínua tenha sido desenvolvido com base nos processos de manufatura, tem havido um forte esforço no sentido de aplicar essa abordagem ao PDP, destacando-se ultimamente o modelo CMMI (CHRISSIS et al., 2006) que busca integrar processos de desenvolvimento de hardware e software em um referencial comum baseado em níveis de maturidade e capabilidade. A dificuldade de aplicar métodos de melhoria contínua ao PDP é analisada por Caffyn (1997). A autora aponta que a intangibilidade, o processo criativo inerente, a necessidade de padronização como fundamento da melhoria de processos e a falta de indicadores de desempenho são as principais dificuldades encontradas na aplicação dos referenciais de melhoria ao PDP.

A utilização de indicadores de desempenho como método de aferição dos resultados das atividades de melhoria do PDP não é algo bastante presente na bibliografia. Entretanto, analisados isoladamente, os indicadores de desempenho são amplamente utilizados pelos autores de PDP. Segundo Cooper e Kleindshmidt (1998), o balanceamento do portfólio de produtos e a sua adequação à estratégia da empresa, dois dos principais objetivos da gestão de portfólio, para serem implementados, precisariam ser sistematicamente gerenciados por meio de um conjunto de indicadores: probabilidade de sucesso comercial, probabilidade de sucesso técnico, adequação a canais de venda, vantagem competitiva possível etc. Os indicadores sugeridos pelos autores têm o objetivo de realizar previsões acerca do resultado do produto e sua adequação à estratégia da empresa.

A Figura 2 apresenta o quadro referencial utilizado por Clark e Fujimoto (1991) para analisar o desempenho de empresas do setor automobilístico sendo baseado no estabelecimento de "[...] um vínculo entre o desempenho do PDP e o objetivo da empresa em lançar novos produtos" (CLARK; FUJIMOTO, 1991, p.71). Qualidade total do produto (TPQ), lead-time e produtividade seriam os indicadores de desempenho do PDP.
TPQ é definida como a extensão com a qual o produto satisfaz os requisitos do consumidor, sejam eles relacionados com atributos objetivos (potência do motor, p.ex.) ou subjetivos (estética, estilo, sensação no volante etc.). O lead-time é definido como a medida de quão rápido uma empresa pode se mover do conceito ao mercado. Considerando o início de um projeto no início do desenvolvimento do conceito, o lead-time é o tempo requerido para definir, projetar e introduzir o produto no mercado. A produtividade, enfim, é definida como o nível de recursos requeridos para que o projeto passe do conceito ao produto comercial, o que inclui horas de trabalho, materiais utilizados em protótipos e quaisquer equipamentos e serviços utilizados.

Os autores desenvolveram uma série de métricas que permitissem analisar o desempenho do PDP nas empresas pesquisadas, assim como sua correlação com o resultado competitivo destas. Dentre as métricas utilizadas, tem-se:

- para medir lead-time: "lead-time de planejamento por projeto", "lead-time de engenharia por projeto", assim como "lead-time por fase do PDP";

- para medir qualidade percebida do produto: percentual de repetição de compra e pontuação do produto em uma classificação de qualidade realizada por experts;

- para medir a qualidade da conformidade do produto: número de falhas técnicas por ano;

- para medir a qualidade do projeto: opinião de projetistas experientes ponderada com valores comerciais dos custos dos produtos analisados;

- para medir produtividade, utilizaram-se as horas de engenharia gastas nas empresas; e

- para avaliar o nível de competitividade global das empresas pesquisadas, os autores levantaram dados de crescimento da participação de mercado das companhias.

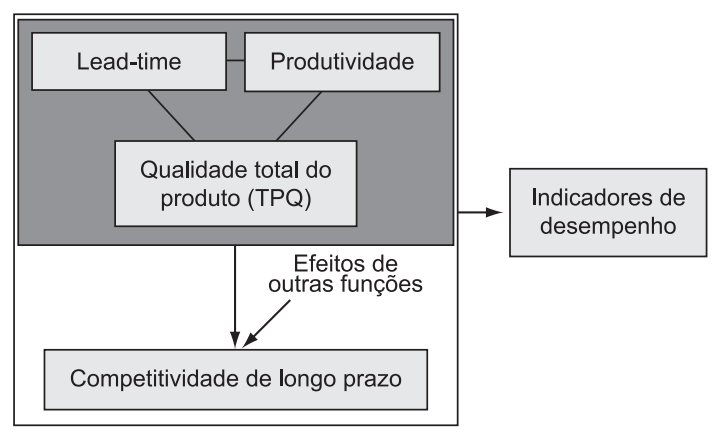

Figura 2. Desempenho do desenvolvimento de produtos. (Adaptado de: CLARK; FUJIMOTO, 1991, p. 70). 
O estudo realizado por Clark e Fujimoto (1991) foi a principal análise do PDP baseada no uso de indicadores de desempenho já que abrangeu a principal indústria de bens de consumo duráveis da atualidade e percorreu empresas de todos os continentes. Outros estudos mais localizados focaram no uso de indicadores de desempenho aplicáveis ao PDP, dentre os quais se destacam os estudos de Griffin e Page (1996), Pawar e Driva (1999) e Prancic e Martins (2003).

Depreende-se desses estudos que os indicadores de desempenho de um processo podem ser calculados com base em um critério de desempenho, por exemplo, custos do produto por volume de itens vendidos, lead-time do projeto pelo tempo de retorno do investimento, número de horas gastas em atividades de teste etc. Porém, existem outros critérios de desempenho que representam o resultado de uma ação de melhoria, por exemplo, redução do lead-time da concepção ao mercado, aumento da produtividade da equipe de engenheiros, aumento da repetição de compra de um determinado grupo de consumidores etc. Os estudos que enfocam o desempenho do PDP comumente fazem uso de critérios, uma vez que não é prática ainda comum o gerenciamento do PDP com base em indicadores.

Do ponto de vista teórico, algumas vezes esses critérios são representados pelos próprios indicadores de desempenho do PDP, fato observável em empresas com uma maior estruturação da medição do desempenho em novos produtos. Outras vezes, um critério reflete a percepção de uma pessoa quanto à melhoria realizada, o que pode, inclusive, ir de encontro aos valores objetivos medidos pelos indicadores. Em Kaplan e Norton (1997), os critérios de desempenho aqui mencionados são denominados pelo autor como "objetivos de desempenho" e se caracterizam por relações de causa-efeito: se determinada ação for realizada então um dado objetivo será atendido.

Como o foco deste trabalho está na medição dos resultados da pesquisa ação, na melhoria do processo, serão utilizados critérios de desempenho para avaliar se a melhoria ocorreu ou não. Esses critérios foram baseados nos estudos sintetizados no presente tópico e no anterior, sendo adaptados a uma situação na qual não havia base de informações gerenciais consolidadas acerca do desempenho do PDP e, portanto, não havia indicadores de desempenho para analisar o PDP. Portanto, a relação de causalidade que se busca é: verificar se houve percepção de melhoria em critérios de desempenho em função das ações de melhoria sumarizadas no item 6 .

\section{Caracterização do Processo de Desenvolvimento de Produtos na empresa pesquisada}

A empresa na qual foi realizado o trabalho aqui descrito foi fundada em 1985 sendo uma respeitada empresa de alta tecnologia do polo tecnológico de São Carlos. Sua trajetória teve origem na USP São Carlos, tendo sido constituída por pesquisadores e técnicos do Instituto de Física. Na época de sua inauguração, a empresa trabalhava com as áreas de filmes finos especiais e aplicações industriais a laser, tendo posteriormente entrado nos mercados de defesa, médico-oftálmico e espacial.

Atualmente, a empresa conta com cerca de 450 funcionários divididos na sede em São Carlos, em um escritório comercial de São Paulo, um escritório em Porto Alegre/RS, outro em Fortaleza/CE, um escritório recém-aberto no Rio de Janeiro e outro em Miami, Estados Unidos. Há representantes na Europa, na Ásia e na Oceania. Todas as unidades realizam operações industriais e de venda e assistência técnica, mas apenas em São Carlos há desenvolvimento de produtos.

Dentre os produtos desenvolvidos pela empresa, tem-se:

- área industrial: medidor a laser para controle de pneus e multiposicionador laser;

- área médica: microscópios cirúrgicos oftálmico e odontológico, retinógrafo digital ADS1.5 e laser fotocoagulador para cirurgia de retina;

- defesa: componentes ópticos e sistemas de detecção a laser para a aeronáutica brasileira, unidades de apontamento e guiamento laser para o exército brasileiro etc.; e

- produtos da área espacial: subsistemas completos para captação e processamento de imagens da Terra a integrarem satélites de monitoramento ambiental.

A empresa adota estratégias de produção diferentes para suas linhas de produto, segundo a classificação de Pires (1995). Há uma linha de produtos de catálogo disponibilizada para produção e venda. Esses produtos, entretanto, não estão disponíveis em estoque sendo produzidos de acordo com o fechamento de pedidos. Os equipamentos médicos, científicos e fabris são produzidos nessa filosofia que configura sistemas de montagem por encomenda (ATO). Há uma outra tipologia de produto que é vendido como projeto mediante contatos feitos pelos departamentos de marketing e engenharia. É fechada uma proposta de fornecimento e o aparelho passa a ser projetado e posteriormente, prototipado, testado, homologado e entregue ao cliente. Esse tipo de manufatura é caracterizado como engenharia por encomenda (ETO).

Há projetos governamentais que podem ser caracterizados como produtos MTO (produção por encomenda), uma vez que, embora o projeto seja financiado pelo contratante, sua entrega não se resume a uma unidade, como no caso dos projetos ETO. Ao invés disso, o produto é fabricado a pedido 
do órgão contratante. Nesta mesma classificação, se encontram serviços de tratamento superficial em lentes oftalmológicas que são realizados em sistemas just-in-time com base nos pedidos enviados pelo varejo.

A Figura 3 apresenta o organograma da empresa pesquisada.

A empresa compõe-se de quatro departamentos, dois deles podendo ser considerados divisões de engenharia, um departamento comercial e um outro de manufatura. O departamento denominado "filmes finos" é responsável pelo desenvolvimento e fabricação de filmes ópticos para o tratamento de lentes de óculos comerciais e para o desenvolvimento de filtros ópticos utilizados em aparelhos de diagnóstico e cirurgia oftalmológica. Essa divisão comporta departamentos de engenharia de produto e de processo independentes que prestam serviços especializados para o PDP da firma.

O departamento de "pesquisa e desenvolvimento" (P\&D) é responsável pelo projeto dos equipamentos dos tipos ATO, MTO e ETO. Ele é composto de um grupo de engenharia formado por engenheiros mecânicos, eletrônicos, de software e físicos e por um grupo de montagem especializada, composto por técnicos em eletrônica e mecânica, o qual é responsável pela integração dos equipamentos de defesa desenvolvidos, assim como, pela montagem dos protótipos de desenvolvimento. Em projetos das áreas espacial e militar, a montagem, a integração, o teste e a entrega das unidades produzidas, depois de homologados os produtos, são realizadas pela equipe de montagem especializada. Projetos do tipo ATO e ETO nascem, comumente, dentro deste departamento.

O departamento comercial mantém um setor de acompanhamento pós-venda do produto e de organização de feiras e eventos de marketing. Sua responsabilidade consiste em propor novos projetos de produtos do tipo ATO da área médica e em acompanhar o grau de satisfação dos clientes com relação a esses produtos. Os projetos ATO se iniciam com um estudo do mercado, sendo depois discutidos pela diretoria antes de serem repassados para o $P \& D$ para que o equipamento seja de fato desenvolvido.
O departamento de "operações industriais" gerencia todo o processo de aquisição, fabricação, montagem e expedição dos produtos desenvolvidos na empresa. Além das operações de manufatura (fabricação e montagem), essa divisão comporta os departamentos de engenharia de produto e de engenharia de processo. Enquanto o P\&D é responsável pelo projeto de produtos inovadores para a empresa, as engenharias de produto e de processo tratam da realização de melhorias incrementais cujo objetivo é a redução dos custos de manufatura e montagem e a introdução do produto na estrutura de fabricação da empresa.

Quando é iniciado o projeto de um novo produto do tipo ATO, o pessoal de marketing especifica o produto e repassa uma breve descrição para o departamento de P\&D. Dentro do P\&D, é estabelecido um "líder de projeto" escolhido na "engenharia". Além disso, são distribuídas responsabilidades para outros integrantes da "engenharia" e da "montagem especializada" de maneira a compor uma equipe de projeto. O líder de projeto distribui as tarefas do trabalho e faz a interface entre projeto e o diretor de $\mathrm{P} \& \mathrm{D}$. Ele é o responsável por cumprir prazos, especificações e uma possível meta de custo para o produto. Não há, entretanto, orçamento especificado para o projeto.

\section{Melhorias realizadas no Processo de Desenvolvimento de Produtos da empresa}

Ao longo de cerca de três anos, o PDP da empresa foi submetido a um intenso trabalho de melhoria em uma pesquisa ação documentada em Barbalho (2006). $\mathrm{O}$ trabalho enfocou os seguintes aspectos:

- Documentação de produto: foram implementadas técnicas de sistematização da concepção e da arquitetura dos produtos desenvolvidos. Mediante estes artefatos foram produzidos documentos de engenharia, fabricação, montagem, PCP, controle de qualidade e assistência técnica. Esse trabalho foi realizado junto ao grupo de engenharia do departamento de P\&D.

- Gestão de projetos: foi implementado um método de planejamento e monitoramento de projetos

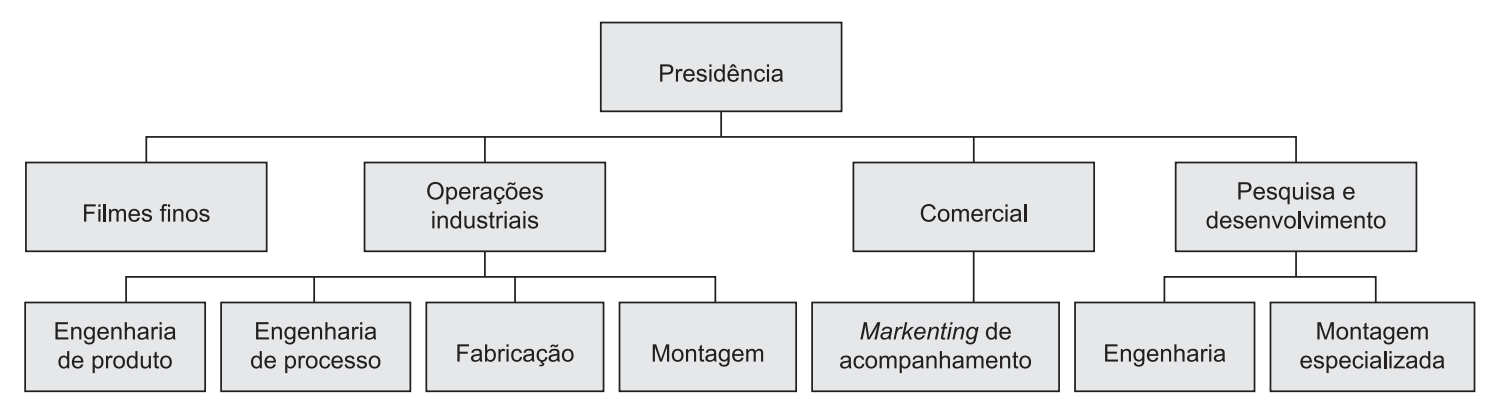

Figura 3. Organograma da empresa pesquisada. 
com base em cronogramas e estruturas de divisão de trabalho. Foram organizados comitês de gestão de projetos para os equipamentos desenvolvidos na área espacial.

- Operações de manufatura: com base na documentação desenvolvida, foram realizados treinamentos com o pessoal de fabricação e montagem. $\mathrm{O}$ processo de montagem, integração e testes dos equipamentos da área médica foram refinados juntamente com o pessoal de manufatura.

A estrutura de produto foi desenvolvida junto ao PCP e uma etapa de produção piloto foi introduzida para facilitar a transferência dos novos produtos para a linha de produção.

A descrição do trabalho de introdução dessas melhorias foge do escopo deste artigo. É, porém, importante ressaltar que o trabalho permitiu a certificação ISO 9001:2000 da área de projetos da empresa, o registro de equipamentos médicos na Agência Nacional de Vigilância Sanitária (ANVISA) e no Foods and Drugs Administration (FDA) e a adequação do PDP da empresa aos rígidos requisitos dos projetos do setor aeroespacial, o qual é regulado por normas europeias e da NASA.

\section{Melhoria de desempenho do Processo de Desenvolvimento de Produtos}

O Quadro 2 apresenta o perfil do grupo pesquisado com o intuito de levantar sua percepção quanto à melhoria do PDP ao final do trabalho mencionado no item anterior. O quadro mostra as áreas funcionais de origem e os papéis dos pesquisados no PDP da empresa.

Os critérios de desempenho utilizados foram selecionados com base na possibilidade de se tornarem indicadores de desempenho para o PDP, conforme as áreas ilustradas na Figura 2 (prazos, qualidade e produtividade): exatidão do planejamento de prazos, melhoria do monitoramento e controle de custos, melhoria no controle de prazos, facilidade de acesso a informações de projeto, facilidade de integração de novos projetistas, grau de alteração de requisitos de produto, redução de reclamações dos departamentos de manufatura e redução de reclamações de clientes. Os critérios de desempenho foram submetidos aos pesquisados por meio das afirmações que constam nos gráficos das Figuras 4 até 11 . No eixo vertical dos gráficos, a escala de concordância ou discordância, apresentada no item 2, mede a percepção de melhoria quanto às afirmações. As respostas foram tabuladas e extraídas as médias de cada indicador para cada grupo pesquisado. A média e o desvio padrão da melhoria geral - considerando todos os critérios analisados - percebida pelo grupo foram também calculados apenas como forma de prover insights analíticos acerca dos dados obtidos.

A Figura 4 apresenta a visão geral dos entrevistados quanto ao grau de melhoria do PDP. Observa-se que o critério de desempenho considerado mais positivo na evolução do PDP da empresa em função das melhorias aplicadas foi a "capacidade de integrar pessoas novas aos projetos". A "exatidão de estimativas de prazos" e o "controle de prazos" foram os critérios com menor percepção de melhoria por parte dos entrevistados.

Nesse, e em todos os gráficos seguintes, uma linha que representa a média da melhoria geral percebida pelos atores é também apresentada. A distribuição das respostas em geral apresenta média de 0,3 (conforme ilustrado na figura) e desvio padrão de 0,4 . Esses valores foram utilizados para verificar o grau de significância das respostas extratificadas por grupo, e os critérios com diferenças significativas em relação à distribuição geral são discutidos ao longo da apresentação dos gráficos seguintes.

A Figura 5 apresenta a percepção de melhoria dos departamentos de engenharia da empresa, ou seja, o departamento de P\&D e o pessoal alocado no setor de engenharia de produto do departamento de operações industriais. Observa-se que para esse público continua havendo maior concordância quanto à "capacidade de integração" e menor quanto à "exatidão de prazos".

A Figura 6 apresenta a percepção de melhoria do pessoal de manufatura da empresa, aqui considerando todas as divisões do departamento de operações industriais, exceto a engenharia de produto. Observa-se uma percepção diferenciada daquela apresentada pela engenharia. O pessoal de manufatura considera que há melhoria significativa em "controle de custos", "controle de informações de projeto" e "redução de reclamações de clientes". Quanto às discordâncias, há um perfil mais próximo ao dos gráficos anteriores: os critérios relacionados a prazos são considerados os mais problemáticos, sendo significativamente negativos para o pessoal de manufatura.

É importante observar que o pessoal de manufatura entende que houve diminuição na quantidade de suas

Quadro 2. Perfil dos entrevistados na segunda etapa de validação do MRM quanto à área funcional.

\begin{tabular}{|cccccccc|}
\hline Total & Engenharia & Manufatura & Marketing & $\begin{array}{c}\text { Alta } \\
\text { direção }\end{array}$ & $\begin{array}{c}\text { Gerentes } \\
\text { funcionais }\end{array}$ & $\begin{array}{c}\text { Líderes de } \\
\text { projeto }\end{array}$ & $\begin{array}{c}\text { Pessoal } \\
\text { técnico }\end{array}$ \\
\hline 20 & 14 & 4 & 2 & 3 & 7 & 5 & 5 \\
\hline
\end{tabular}


reclamações acerca dos projetos, corroborando com a opinião da engenharia (Figura 5).

A Figura 7 apresenta a percepção de melhoria do pessoal de marketing. Observa-se uma grande diferenciação com relação aos dois grupos anteriores. Marketing considera que os projetos são mal controlados em termos de prazos e de custos. Esse comportamento pode decorrer do fato de que os vendedores fazem pressão pela redução dos prazos de projeto; pela redução do custo do projeto, o que diminui as metas de volume de vendas para a amortização do investimento - diminuindo a pressão da alta direção para que mais produtos sejam vendidos -; e pelo aumento das margens, o que implica na redução dos custos do produto, aumentando a possibilidade de o vendedor barganhar com preço do produto junto a clientes potenciais.

Marketing foi o único grupo pesquisado que considerou que há maior exatidão na estimativa de prazos do projeto - mesmo não sendo critério com percepção de melhoria significativa quando comparado com a distribuição geral dos pesquisados (Figura 4) -, o que pode estar relacionado com o fato de ser ele o

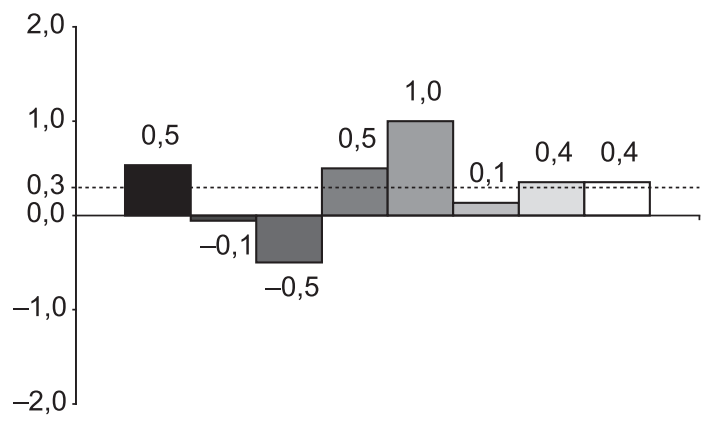

Atualmente os projetos são mais bem controlados em termos de custos

Atualmente os projetos são mais bem controlados em termos de prazos

Atualmente se consegue estimar com exatidão os prazos necessários para realizar as atividades

Atualmente há um eficiente controle sobre as informações geradas ao longo do projeto

Atualmente há maior capacidade de integrar pessoas novas aos projetos

Atualmente há menos mudanças nas

$\square$ especificações que precisam ser atingidas pelo projeto ao longo de seu desenvolvimento

Atualmente há menos reclamações dos setores

$\square$ de manufatura e montagem quanto às informações geradas nos projetos

Atualmente há menos reclamações dos clientes quanto aos produtos desenvolvidos

Figura 4. Graus de melhorias dos critérios de desempenho pesquisados. setor responsável por estabelecer metas de prazo para os projetos da área médica. Consideram, portanto, que o problema de prazo é mais vinculado com a falta de controle de prazos (atividade realizada pela engenharia) que com a inexatidão das previsões e metas. $O$ pessoal de marketing considera, ainda de acordo com a Figura 7, que há maior capacidade de integração de pessoas novas nos projetos - embora não significativo - e acredita que houve redução de reclamação de clientes com os novos produtos da empresa.

Intriga o fato de o pessoal de marketing ter percepção, de maneira significativa, que não tem havido "menos mudanças de especificações" dos

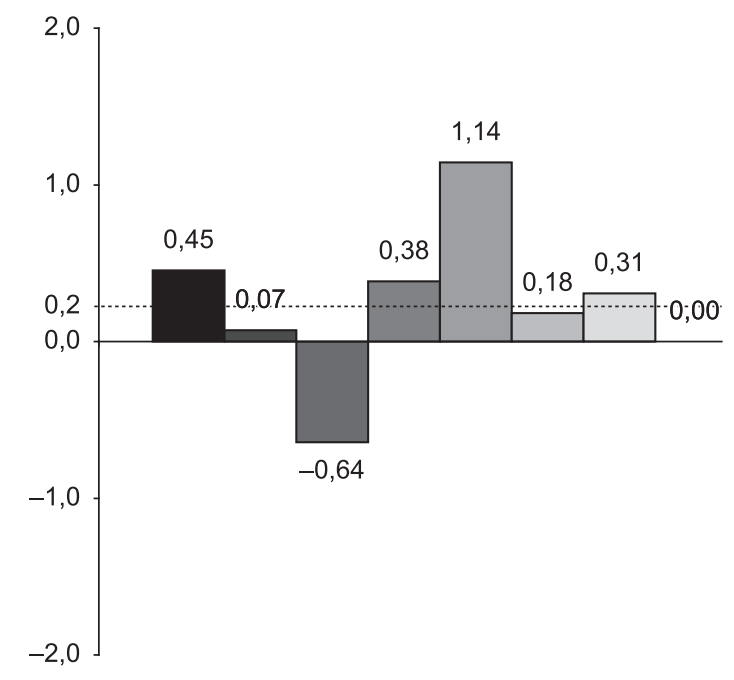

Atualmente os projetos são mais bem controlados em termos de custos

Atualmente os projetos são mais bem controlados em termos de prazos

Atualmente se consegue estimar com exatidão os prazos necessários para realizar as atividades

Atualmente há um eficiente controle sobre as informações geradas ao longo do projeto

Atualmente há maior capacidade de integrar pessoas novas aos projetos

Atualmente há menos mudanças nas especificações que precisam ser atingidas pelo projeto ao longo de seu desenvolvimento

Atualmente há menos reclamações dos setores

de manufatura e montagem quanto às informações geradas nos projetos

Atualmente há menos reclamações dos clientes quanto aos produtos desenvolvidos

Figura 5. Graus de melhorias dos critérios de desempenho conforme opinião da engenharia. 
produtos, pois a mudança de especificações é originada de marketing e tanto a manufatura quanto a engenharia consideraram que houve redução da mudança de requisitos dos produtos depois de iniciados os projetos - porém não têm uma percepção de melhoria significativa nesse indicador. Uma vez que a empresa não mantém um sistema de gerenciamento de requisitos de produtos, pode-se formular a hipótese de que, embora o volume de alterações de requisitos seja ainda grande, há uma redução com relação a um momento anterior na empresa. Além disso, é provável que em um momento anterior houvesse uma maior quantidade de atores na empresa que traziam requisitos de projeto, o que, atualmente, é realizado apenas pelo diretor responsável pelo departamento de marketing, o qual foi entrevistado e para quem houve aumento de mudança de especificações.

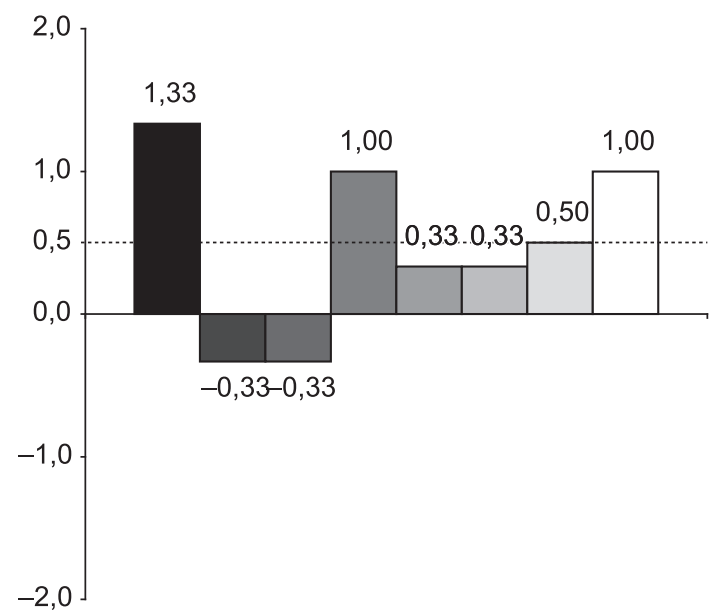

Atualmente os projetos são mais bem controlados em termos de custos

Atualmente os projetos são mais bem controlados em termos de prazos

Atualmente se consegue estimar com exatidão os prazos necessários para realizar as atividades

Atualmente há um eficiente controle sobre as informações geradas ao longo do projeto

Atualmente há maior capacidade de integrar pessoas novas aos projetos

Atualmente há menos mudanças nas

$\square$ especificações que precisam ser atingidas pelo projeto ao longo de seu desenvolvimento

Atualmente há menos reclamações dos setores

$\square$ de manufatura e montagem quanto às informações geradas nos projetos

Atualmente há menos reclamações dos clientes quanto aos produtos desenvolvidos

Figura 6. Graus de melhorias dos critérios de desempenho conforme opinião da manufatura.
Em suma, analisando conjuntamente os dados da Figura 5 com a Figura 6 e a Figura 7, pode-se verificar que os prazos não têm sido considerados bem gerenciados, porém os diferentes atores consideram que há melhorias em suas respectivas áreas: a engenharia, quanto ao controle de informações e a capacidade de integração de novos projetistas; a manufatura, quanto à redução das reclamações dela própria em relação à engenharia e dos clientes em relação aos equipamentos entregues; e marketing, quanto à redução da reclamação de clientes e exatidão de estimativas de prazos para os projetos. Portanto, os dados demonstram forte tendência pela defesa do departamento de origem do pesquisado nas suas respostas quanto à melhoria do PDP.

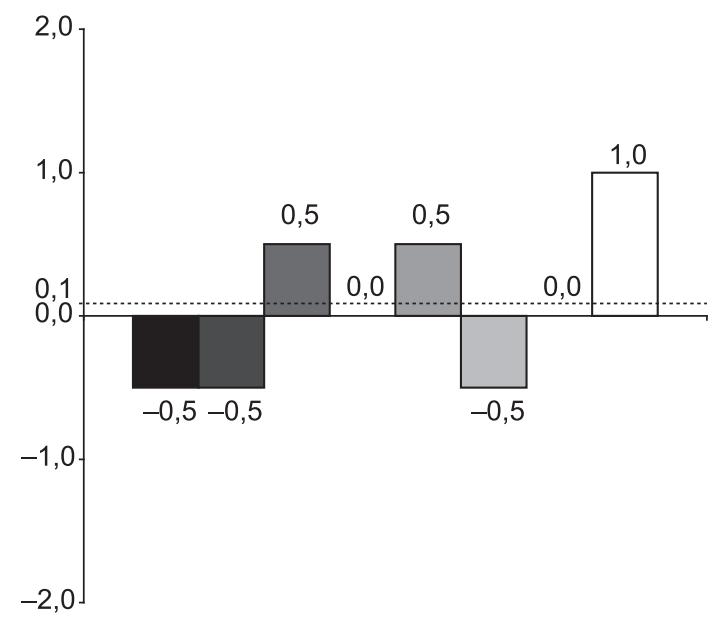

Atualmente os projetos são mais bem

controlados em termos de custos

Atualmente os projetos são mais bem controlados em termos de prazos

Atualmente se consegue estimar com exatidão os prazos necessários para realizar as atividades

Atualmente há um eficiente controle sobre as informações geradas ao longo do projeto

Atualmente há maior capacidade de integrar pessoas novas aos projetos

Atualmente há menos mudanças nas

especificações que precisam ser atingidas pelo projeto ao longo de seu desenvolvimento

Atualmente há menos reclamações dos setores

$\square$ de manufatura e montagem quanto às informações geradas nos projetos

Atualmente há menos reclamações dos clientes quanto aos produtos desenvolvidos

Figura 7. Graus de melhorias dos critérios de desempenho conforme opinião do marketing. 
A partir da Figura 8, discutem-se os resultados em função do papel do entrevistado no PDP. A Figura 8 apresenta o gráfico com a opinião da alta direção.

A alta direção percebe problemas quanto às reclamações da manufatura, entretanto considera que há menor volume de reclamações de clientes e que há maior controle sobre as informações geradas ao longo dos projetos. Considera ainda que há maior capacidade de integração de novas pessoas aos projetos. Pode-se levantar a hipótese de que o maior controle de informações de projeto permite uma mais fácil integração de pessoas novas aos projetos. Embora tenha havido uma percepção de que existe uma maior quantidade de reclamações da manufatura, a alta direção observa uma redução nas reclamações de clientes. É importante observar que a alta direção não considera ter havido melhoria na gestão de prazos e custos dos projetos.

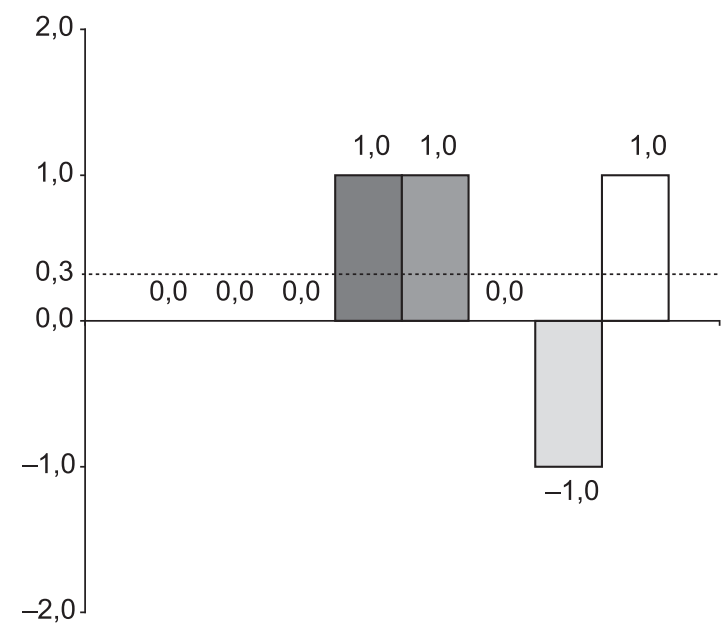

Atualmente os projetos são mais bem controlados em termos de custos

Atualmente os projetos são mais bem controlados em termos de prazos

Atualmente se consegue estimar com exatidão os prazos necessários para realizar as atividades

Atualmente há um eficiente controle sobre as informações geradas ao longo do projeto

Atualmente há maior capacidade de integrar pessoas novas aos projetos

Atualmente há menos mudanças nas especificações que precisam ser atingidas pelo projeto ao longo de seu desenvolvimento

Atualmente há menos reclamações dos setores

$\square$ de manufatura e montagem quanto às informações geradas nos projetos

Atualmente há menos reclamações dos clientes quanto aos produtos desenvolvidos

Figura 8. Graus de melhorias dos critérios de desempenho conforme opinião da alta direção.
A Figura 9 apresenta os graus de concordância e discordância percebidos pelos gerentes funcionais. Diferentemente da alta direção, os gerentes funcionais consideram que tem havido melhoria de controle de custos e prazos - embora para este último a percepção de melhoria não seja significativa. Isso pode ser explicado pelo fato de a empresa adotar uma estrutura funcional e, portanto, delegar à gerência funcional a gestão de prazos e custos dos projetos.

A exatidão dos prazos estimados é o único aspecto no qual houve discordância dos gerentes funcionais, sendo significativa com relação à opinião geral dos entrevistados (Figura 4). Interessante o fato de que a alta gerência, principal responsável por imputar metas temporais aos projetos, não discorda da melhoria desse indicador, enquanto que a gerência funcional considera esse aspecto negativo em termos de melhoria. Ou seja, pode-se sugerir como análise

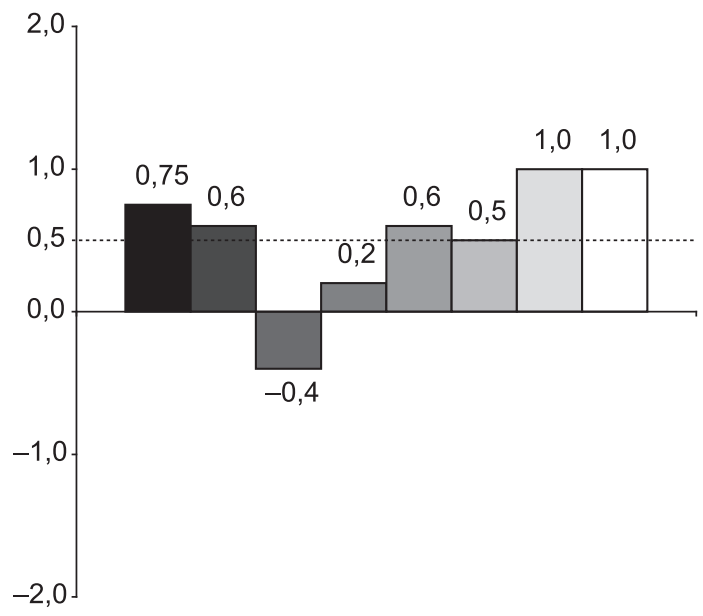

Atualmente os projetos são mais bem controlados em termos de custos

Atualmente os projetos são mais bem controlados em termos de prazos

Atualmente se consegue estimar com exatidão os prazos necessários para realizar as atividades

Atualmente há um eficiente controle sobre as informações geradas ao longo do projeto

Atualmente há maior capacidade de integrar pessoas novas aos projetos

Atualmente há menos mudanças nas

$\square$ especificações que precisam ser atingidas pelo projeto ao longo de seu desenvolvimento

Atualmente há menos reclamações dos setores

$\square$ de manufatura e montagem quanto às informações geradas nos projetos

Atualmente há menos reclamações dos clientes quanto aos produtos desenvolvidos

Figura 9. Graus de melhorias dos critérios de desempenho conforme opinião dos gerentes funcionais. 
desses dados que os prazos a serem seguidos pelos gerentes funcionais são considerados irreais por estes. Eles gerenciam os prazos para atender às estimativas, mas não conseguem. Então a alta gerência avalia que os prazos não são bem administrados (Figura 8).

A Figura 10 apresenta o perfil de concordânciadiscordância dos líderes de projeto. Uma vez que têm responsabilidade técnica sobre o projeto, mas não os gerenciam já que a empresa adota estrutura funcional, esses atores são os mais pressionados ao longo dos projetos de novos produtos. A pressão se reflete na Figura 10 pelos graus de discordância quanto às reclamações de manufatura (não significativa) e clientes e pelo grau de discordância quanto à exatidão dos prazos e o seu controle, em ambos os casos os valores mais negativos de todos os analisados. Vale ressaltar que, esse grupo, formado por pessoas da

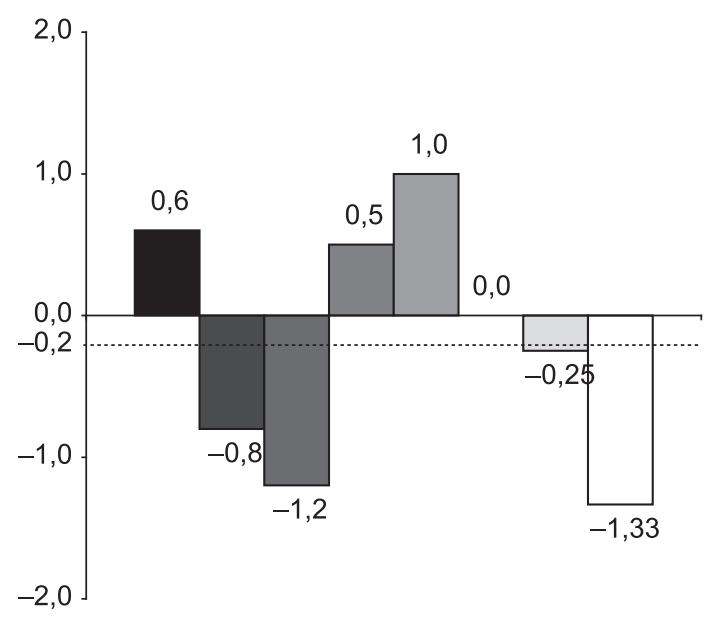

Atualmente os projetos são mais bem controlados em termos de custos

Atualmente os projetos são mais bem controlados em termos de prazos

Atualmente se consegue estimar com exatidão os prazos necessários para realizar as atividades

Atualmente há um eficiente controle sobre as $\square$ informações geradas ao longo do projeto

Atualmente há maior capacidade de integrar pessoas novas aos projetos

Atualmente há menos mudanças nas $\square$ especificações que precisam ser atingidas pelo projeto ao longo de seu desenvolvimento

Atualmente há menos reclamações dos setores

$\square$ de manufatura e montagem quanto às informações geradas nos projetos

Atualmente há menos reclamações dos clientes quanto aos produtos desenvolvidos

Figura 10. Graus de melhorias dos critérios de desempenho conforme opinião dos líderes de projeto. engenharia, apresenta a menor média de percepção geral de melhoria entre todos os demais.

Os líderes de projeto têm percepção de que houve melhoria quanto ao controle de informações ao longo dos projetos - porém não significativamente, e que há uma significativa maior facilidade de integrar novos membros às equipes de projeto. Esse aspecto ressalta aos líderes em função da necessidade de agregar outras pessoas aos projetos nos momentos de conclusão de etapas importantes e de maior pressão nas suas atividades. O controle de custos também é considerado positivo, embora não significativamente.

Enfim, a Figura 11 apresenta os graus de melhoria percebidos pelas equipes de projeto. Neste grupo, encontra-se a percepção mais positiva identificada ao longo da pesquisa, o que se deu quanto à integração de pessoas novas aos projetos, aspecto que afeta

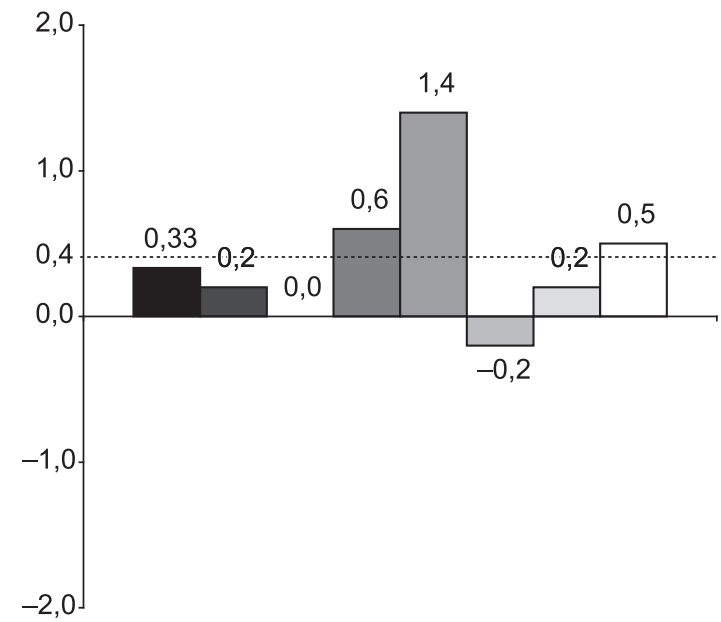

Atualmente os projetos são mais bem controlados em termos de custos

Atualmente os projetos são mais bem controlados em termos de prazos

Atualmente se consegue estimar com exatidão os prazos necessários para realizar as atividades

Atualmente há um eficiente controle sobre as informações geradas ao longo do projeto

Atualmente há maior capacidade de integrar pessoas novas aos projetos

Atualmente há menos mudanças nas

$\square$ especificações que precisam ser atingidas pelo projeto ao longo de seu desenvolvimento

Atualmente há menos reclamações dos setores

$\square$ de manufatura e montagem quanto às informações geradas nos projetos

Atualmente há menos reclamações dos clientes quanto aos produtos desenvolvidos

Figura 11. Graus de melhorias dos critérios de desempenho conforme opinião da equipe de projeto. 
diretamente sua capacidade de migrar de um projeto para outro ao longo do tempo, algo fundamental na estrutura funcional adotada na empresa. Há concordância não significativa quanto a outros aspectos pesquisados. Por exemplo, o time de projeto considera que há mais eficiente controle sobre as informações geradas nos projetos, o que pode ser explicado pelo fato de que esses atores são os responsáveis pela montagem e teste dos protótipos dos novos produtos sendo, consequentemente, usuários diretos da documentação de projeto gerada pelos engenheiros. Considerando que é o time de projeto o responsável pela transferência do processo de montagem e teste do produto para os departamentos de manufatura; a percepção ilustrada na Figura 11 quanto à redução de reclamações de manufatura e de clientes é algo que vai de encontro ao seu interesse: “... eu treinei; o pessoal monta melhor; eu ensinei como testa e chega um produto melhor no cliente".

Novamente a exatidão na estimativa de prazos é considerada de pouco grau de melhoria e, corroborando com a opinião do pessoal de marketing, o time de projeto discorda de ter havido qualquer grau de melhoria em termos de redução de mudanças nas especificações do produto, uma discordância significativa quando comparada ao resultado geral dos entrevistados (Figura 4).

\section{Considerações finais e conclusões}

Esse artigo analisou a influência do setor funcional e do papel desempenhado por um determinado ator no processo de desenvolvimento de produtos sobre a percepção de melhoria acerca desse processo.

Foram realizadas melhorias no PDP da empresa pesquisada no sentido de formalizar o planejamento de projetos e no sentido de melhor documentar o produto para os departamentos de manufatura e para a realização de registro em organismos regulatórios. Comprovou-se pelas entrevistas que houve esforço inédito para a empresa no sentido de facilitar a transição do projeto entre engenharia e manufatura. Como a empresa optou por adotar uma estrutura funcional e essa transição sempre foi bastante traumática, foi dada uma forte ênfase tanto no aspecto documental, como na promoção de reuniões, treinamentos e trabalhos conjuntos de maneira a reduzir as barreiras funcionais entre esses departamentos. Trabalho similar não houve quanto à interface entre o departamento comercial e o P\&D.

Portanto, a expectativa do pesquisador, quanto aos dados coletados a título de avaliação da pesquisa ação realizada, seria de redução da quantidade de reclamações da manufatura, o que se verificou, na opinião da alta direção da empresa. Quanto às reclamações de clientes e à modificação das especificações de projeto não havia expectativa prévia já que foram áreas pouco abordadas ao longo do trabalho de implementação de melhorias.

Conforme mencionado quando da descrição das melhorias implementadas, foi realizado um esforço de planejamento dos prazos dos projetos. Esperava-se que houvesse percepção de melhoria em prazos, hipótese não comprovada pelos dados, os quais mostraram que o controle de prazos e, especialmente, a realização de estimativas de prazos, são considerados aspectos deficientes ou que pioraram no PDP da empresa. Uma análise dessa percepção foge ao escopo do artigo.

Os dados apresentados desde a Figura 4 até a Figura 11 mostram que a percepção de melhoria do PDP na empresa depende fortemente da posição do entrevistado na sua estrutura organizacional. $\mathrm{O}$ pessoal de engenharia enfatizou a capacidade de integrar pessoas aos projetos, a manufatura enfatizou a redução das reclamações dos clientes, assim como, por motivos diferentes, o fez o pessoal de marketing. O mesmo comportamento pode ser observado na estratificação relacionada com o papel do respondente no PDP da empresa.

Entretanto, os dados mostram também que o papel do respondente no PDP da empresa se sobrepõe e altera a visão de melhoria de uma determinada área funcional sobre parâmetros de desempenho do PDP. Isso pode ser verificado na comparação entre o gráfico de perfil de concordância-discordância da engenharia (Figura 5) com o apresentado pelos líderes de projeto (Figura 10) e pelo time de projeto (Figura 11). Tanto líderes quanto time de projeto estão alocados na mesma área funcional, porém, quando analisados como departamento (Figura 5), apresentam um perfil que facilmente os difere de marketing e da manufatura; e quando estratificados com base nos papéis que desenvolvem no PDP apresentam uma grande diferença comparativa em termos de percepção de melhoria entre si (Figuras 10 e 11) com variações que não podem ser explicadas pela área funcional na qual estão enquadrados, mas em função de suas responsabilidades e, portanto, daquilo que são cobrados ao longo dos projetos, conforme apresentado quando da discussão de cada gráfico.

A implicação do estudo é que, seja na realização de pesquisas acadêmicas do tipo survey ou estudos de casos múltiplos, seja na realização de atividades que visem o monitoramento do desempenho do PDP em uma determinada empresa, deve-se observar a área funcional do respondente e seu papel dentro do PDP. Em última análise, isso significa que o interesse do respondente sobre o desempenho do PDP da empresa é determinante em sua resposta sobre a melhoria desse processo. A necessidade de levantamento de dados factuais e o monitoramento de indicadores objetivos parecem fundamentais para que essa subjetividade seja ponderada e um entendimento mais próximo da realidade seja possível. 
Do ponto de vista empresarial, o estudo permitiu verificar que o construto "percepção de melhoria" aqui utilizado demonstrou como as unidades organizacionais do PDP incorporam a ideia da melhoria, compreendendo-a sob seu ponto de vista particular e dando significado diferenciado aos resultados atingidos com o trabalho de melhoria em si. A análise destas percepções, adicionalmente, pode permitir estabelecer estratégias de ação sobre os grupos envolvidos no PDP de forma a minimizar obstáculos às mudanças necessárias para racionalizar e aumentar a eficiência e eficácia deste processo em uma dada situação.

\section{Referências}

AMARAL, D. C. Colaboração cliente-fornecedor no desenvolvimento de produto: integração, escopo e qualidade do projeto do produto - estudos de caso na indústria automobilística brasileira. 1997. 203 p. Dissertação (Mestrado) - Universidade Federal de São Carlos, São Carlos.

AKGÜN, A. E. et al. Learning process in new product development teams and effects on product success: a socio-cognitive perspective. Industrial Marketing Management, v. 35, n. 1, p. 210-224, 2006.

BARBALHO, S. C. M. Modelo de referência para o desenvolvimento de produtos mecatrônicos: proposta e aplicações. 2006. Tese (Doutorado) - Escola de Engenharia de São Carlos, Universidade de São Paulo, São Carlos/SP.

BARRETO, A. et al. Staffing a software project: a constraint satisfaction and optimization-based approach. Computers and Operations Research, doi: 10.1016/j. cor.2007.01.010, 2007.

CAFFYN, S. Extending Continuous Improvement to the New Product Development. R\&D Management, v. 27, n. 3, p. 253-267, 1997.

CAMPBELL, A. J.; COOPER, R. Do customer partnerships improve new product success rates? Industrial Marketing Management, v. 28, n. 5, p. 507-519, 1999.

CHIVA, R.; ALEGRE, J. Linking design management skills and design function organization: an empirical study of Spanish and Italian ceramic tile producers. Technovation, v. 27, n. 10, p. 616-627, 2007.

CLARK, K. B.; FUJIMOTO, T. Product development performance: strategy, organization and management in the world auto industry. Massachussets, United States: Harvard Business School Press, 1991.

CLAUSING, D. Total Quality Development: a step-bystep guide to world-class concurrent engineering. New York: The American Society of Mechanical Engineers, 1993.

COOPER, R. Benchmarking new product performance: results of the best practices study. European Management Journal, v. 16, n. 1, p. 1-17, 1998.

COOPER, R.; KLEINSCHMIDT, E. J. Benchmarking the firm's critical success factors in new product development. Journal of Product Innovation Mangament, v. 12, n. 5, p. 374-391, 1995.
Portifólio Management for New Products. Massachussets, United States: Perseus Books, 1998.

COUGHLAN, P.; COGHLAN, D. Action Research. In: C. KARLSSON. Researching Operations Management. 1 ed. New York: Routledge, 2009. p. 236-262.

CHRISSIS, M. B. et. al. CMMI: Guidelines or process integration and product improvement. Boston, Massachussets, United States, 2003.

GRIFFIN, A.; PAGE, A. L. PDMA success measurement project: recommended measures for product development success and failure. Journal of Product Innovation Mangament, v. 13, n. 6, p. 478-494, 1996.

GRIFFIN, A. PDMA research on New Product Development practices: updating trends and benchmarking best practices. Journal of Product Innovation Mangament, v. 14, p. 429-458, 1997.

GRYNA, F. M. Quality Planning \& Analysis: from product development through use. 4 ed. New Jersey: McGraw Hill, 2001.

HAMMER, M.; CHAMPY, J. Reengenharia: revolucionando a empresa em função dos clientes, da concorrência e das grandes mudanças da gerência. Rio de Janeiro: Campus, 1994.

IMAI, M. Kaizen: a estratégia para o sucesso competitivo. Tradução Cecília Fagnani Lucca. 3 ed. IMAM, 1990.

KAPLAN, R. S.; NORTON, D. P. A Estratégia em ação: balanced scorecard. Tradução: Luiz Euclides Trindade Frazão Filho. Rio de Janeiro/RJ: Editora Campus, 1997.

KODAMA, M. Innovation and knowledge creation through leadership-based strategic community: case study on high-tech company in Japan. Technovation, v. 27, n. 3, p. 115-132, 2007.

KURANA, A.; ROSENTHAL, S. R. Towards holistic "front ends" in new product development. Journal of Product Innovation Mangament, v. 15, p. 57-74, 1998.

MARKHAM, S. K.; GRIFFIN, A. The breakfast of champions: associations between champions and product development environments, practices and performance. Journal of Product Innovation Mangament, v. 15, p. 436-454, 1998.

MATSUI, Y. Contribution of manufacturing departments to technology development: an empirical analysis for machinery, electrical and electronics, and automobile plants in Japan. International Journal of Production Economics, v. 80, p. 185-197, 2002.

McIVOR, R.; HUMPHREYS, P.; CADDEN, T. Supply involvment in product development in the electronics industry: a case study. Journal of Engineering Technology Management, v. 23, p. 374-397, 2006.

MERLO, C.; GIRARD, PH. Information system modelling for engineering design co-ordination. Computers in industry, v. 55, p. 317-334, 2004.

MILLSON, M. R.; WILEMON, D. Driving new product success in the electrical equipment manufacturing industry. Technovation, v. 26, n. 11, p. 1268-1286, 2006.

NONAKA, I.; TAKEUSCHI, I. Criação de conhecimento na empresa. Tradução de Ana Beatriz Rodrigues, Priscilla Martins Celeste. Rio de Janeiro: Campus, 1997. 
PAWAR, K. S.; DRIVA, H. Performance measurement for product design and development in a manufacturing environment. International Journal of Production Economics, v. 60-61, n. 1, p. 61-68, 1999.

PRANCIC, E.; MARTINS, R. A. Uma revisão teórica sobre a medição de desempenho do processo de desenvolvimento do produto. In: CONGRESSO BRASILEIRO DE GESTÃO DO DESENVOLVIMENTO DE PRODUTOS, 4, 2003, Gramado/RS. Anais... CD-ROM

PROJECT MANAGEMENT INSTITUTE (PMI). Project Management Body of Knowledge - PMBOK. [S.1.]: [s.n.], 2005. (Tradução Livre, Capítulo de Minas Gerais do PMI).

PIRES, S. R. I. Gestão estratégica da produção. Piracicaba/ SP: Unimep, 1995
SOSA, M. E.; EPPINGER, S. D.; ROWLES, C. M. The misalignment of product architecture and organizational structure in complex product development. Management Science, v. 50, n. 12, p. 1674-1689, 2004.

THIOLLENT, M. Metodologia da pesquisa-ação. São Paulo/SP: Editora Cortez, 2002.

ULRICH, K. T.; EPPINGER, S. D. Product design and development. United States: McGraw-Hill Inc., 1995.

WHEELWRIGHT, S. C.; CLARK, K. B. Revolutionizing product development process: quantum leaps in speed, efficiency, and quality. New York, United States: The Free Press, 1992.

YIN, R. Estudo de caso: planejamento e métodos. Tradução de Daniel Grassi. Revisão de Cláudio Damacena. 2 ed. Porto Alegre: Bookman, 2001. 